\title{
Tuberculosis with Pulmonary Cavitations in Two Siblings of Internally Displaced Couple-A Case Report
}

\author{
YaubaMS,${ }^{1}$ Ahmed $\mathrm{H},{ }^{2}$ Imoudu IA, ${ }^{2}$ Yusuf MO, ${ }^{2}$ Makarfi $\mathrm{HU}^{2}$ \\ ${ }^{1}$ (Department of Paediatrics, University of Maiduguri College of Medical Sciences, Nigeria) \\ ${ }_{2}^{2}$ (Department of Paediatrics, Federal Medical Centre, Azare, Nigeria)
}

\begin{abstract}
Tuberculosis (TB) in children is a significant cause of morbidity and mortality. Occurrence of cavitory tuberculosis in children is not very common and is associated with greater degree of infectiousness. We report a 6 year old girl and 10 months old boy both from internally displaced couple and they presented to the Medical Centre with chronic cough, fever, chest pain, difficulty in breathing and weight loss. Their chests $X$ rays have revealed multiple cavitary lesions and were being managed with anti TB drugs. However, the older sibling died after 11 days of commencement of anti TB while the parents absconded with the younger child due to the death of the elder sibling. Pulmonary cavitary tuberculosis, though not very common in children, may still occur, especially in the immono-compromised like the malnourished and overcrowded internally displaced population. It is worthwhile to note the occurrence of pulmonary cavitary TB in children in an internally displaced setting like this as this may lead high TB infection and transmission rate as a result of overcrowding. An effective TB surveillance system in this setting is, therefore, needed to reduce the burden of TB in crowded population.
\end{abstract}

Key words: Internally displaced couple, siblings, cavitary tuberculosis

\section{Introduction}

Children suffer from tuberculosis-related morbidity and mortality, particularly in endemic areas like Nigeria.Pulmonary cavitarytuberculosis, adult type tuberculosis, in children is rare and infectious condition. ${ }^{1}$ Pulmonary tuberculosis in children presenting as cavity is a problem because it acts as a source of infection (which is responsible for the persistence of the disease in the community) and is often non-responsive to therapy [1]. This condition is still seen in areas of high TB prevalence like India due to infection with resistant bacilli [1].Children contribute a substantial proportion of the global tuberculosis burden with the prevalence ranging from $11 \%$ to $13.7 \%$ [2]. There has been a resurgence of childhood tuberculosis cases due to HIV pandemic,lack of case reporting,contact tracing, screening, use of preventive chemotherapy, and poor nutrition [3].We present this uncommoncondition in two siblings who were from internally displaced couple due to insecurity as this can lead to increased burden of tuberculosis in children.

\subsection{CASE 1}

\section{Case Presentation}

A 6 year-old girl presented with chronic cough, low grade continuous fever, and weight loss for two months duration. Cough was non paroxysmal, non-whoopingand there was associated difficulty in breathing and refusal to feed. There was no history of contact with a chronically coughing adult andshe was not given BCG vaccine. Thechild was the $5^{\text {th }}$ of seven children in the family. Mother is full time house wife while the father is a peasant farmer. The youngest brother (10 months old) was also on admission for tuberculosis. On examination she was found to be chronically ill, afebrile $\left(36.6^{\circ} \mathrm{C}\right.$ ), wasted (weight of $75 \%$ of expected) and stunted (length was $84 \%$ of expected) with significant peripheral lymphadeopathy. She was tachypnoeic(respiratory rate of 48 cycles/ minutes) and dyspnoeic, the trachea was central, with dull percussion notes on the right middle and lower zones, with reduced breath sound intensity bilaterally, bronchial breath soundsand bilateral widespread coarse crepitations. Other systemic examination findings were normal. The patient was managed as a case of pulmonary tuberculosis. She was commenced on anti tuberculous drugs. Chest X-ray revealed multiple cavitarylessions with near homogeneous opacity on both the lung fields(Fig.I). Sputum and pleural pus AFB were negative and mantoux test non-reactive. Total WBC count was $29.1 \times 10^{3} / \mu \mathrm{L}$, Lymphocytes was $11.1 \%$, neutrophils was $85.4 \%, \mathrm{PCV}$ was $26 \%$ and ESR was $101 \mathrm{~mm} /$ hour. Serum electrolytes urea and creatinine were within normal limits. Human immunodeficiency virus screening was non- reactive. She was commenced on anti tuberculous drugs and patient died after 13 days of admission but 11 days of commencement of anti tuberculous drugs. 
Figure I: A chest radiograph of a 6-year old girl showingcavitary lesionson both lung fields

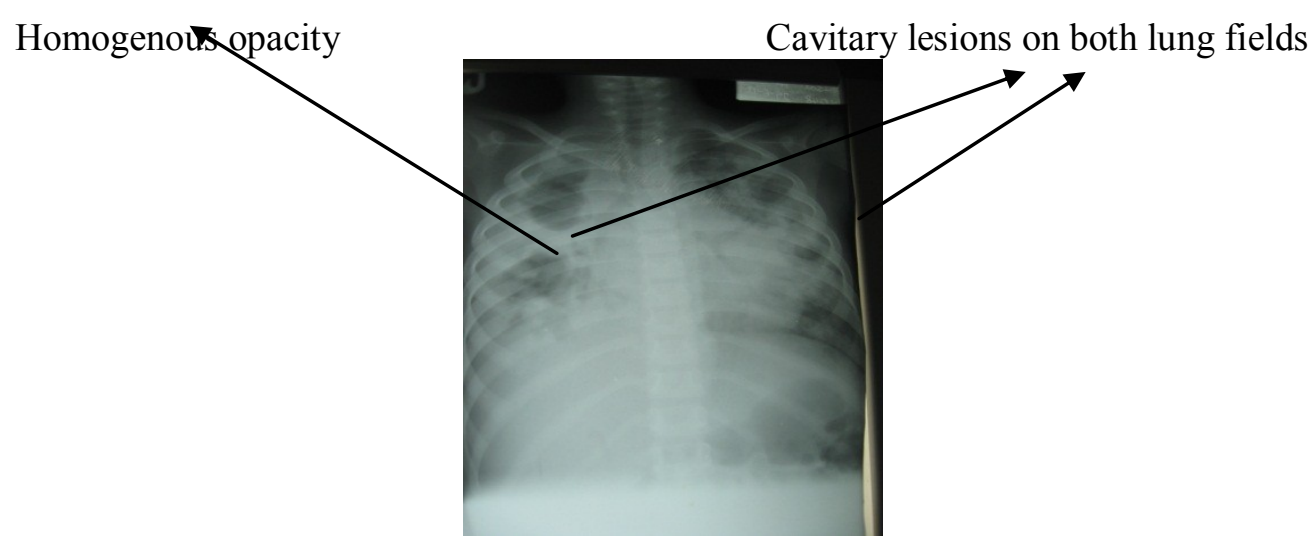

\subsection{CASE 2}

A 10 months old boy presented with low grade, continuous fever and cough for six weeks duration and refusal to feed for three weeks duration. Cough was non paroxysmal, non-whooping with associated contact with six-year old chronically coughing elder sibling. There was associated weight loss and refusal to feed and he was not given BCG vaccine. There was poor nutritional history and developmental milestones regressed. Pregnancy, delivery and neonatal period were uneventful. Child was the $7^{\text {th }}$ of the seven children from internally displaced family. Mother was a full-time house wife while father was a peasant farmer. The elder sibling was also on admission and being managed for pulmonary tuberculosis but died after 13 days of admission but 11 days of commencement of anti-tuberculous treatment. On examination he was found to be chronically ill, febrile $\left(38.8^{\circ} \mathrm{C}\right.$ ), wasted (weight of $52 \%$ of expected) and stunted (length was $86 \%$ of expected) with significant peripheral lymphadenopathy.He was tachypnoeic(respiratory rate of $52 \mathrm{cycles} / \mathrm{minutes}$ ) and dyspnoeic, trachea was central, with vesicularlbreath soundsand widespread coarse crepitations. Other systemic examination findings were normal. He was commenced on anti tuberculous drugsbased on score chart for the diagnosis of TB in children prepared by Federal Ministry of Health andchest X-ray findings which revealed cavitorylessionswith areas of opacities on both the left lung fields (fig. II). Early morning gastric aspirate Acid Fast Baccilli was negative and Mantoux test non-reactive. Total White Blood Cell count was $11.4 \times 10^{3} / \mu \mathrm{L}$, lymphocytes was $31.3 \%$, neutrophils was $61.1 \%, \mathrm{Hb}$ was $5.5 \mathrm{~g} / \mathrm{dl}$ and ESR was $43 \mathrm{~mm} /$ hour. Serum electrolytes, urea and creatinine were within normal limits. Human immunodeficiency virus screening was nonreactive. Motherabsconded with him due to the death of the elder sib who was also being treated for TB 11 days after commencement of anti TB drugs.

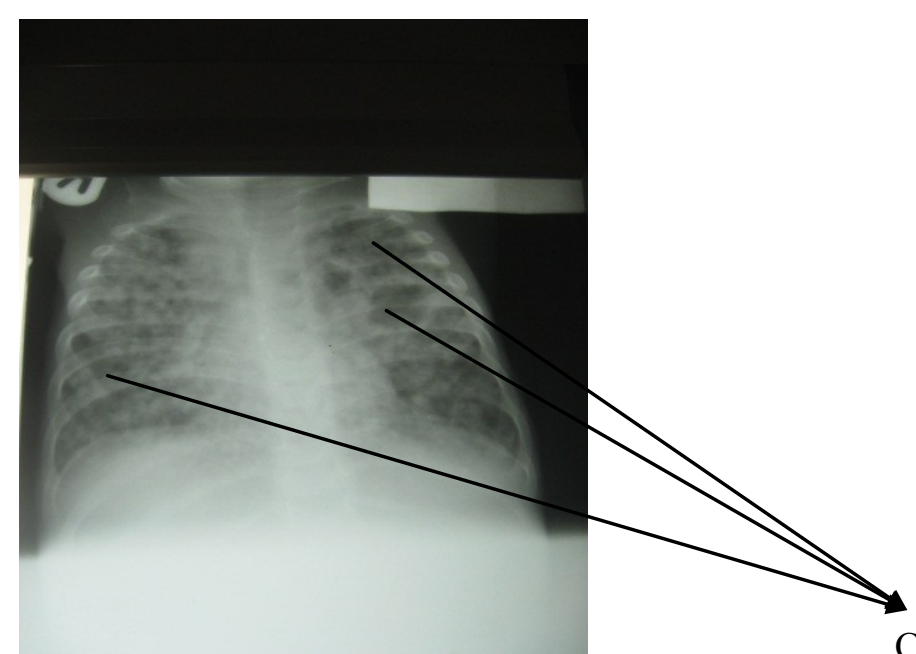

Cavitary lesions on both lung fields

Figure II: A chest Radiograph of a 10-months old boy showing multiple cavitary lesions on both lung fields 


\section{Discusion}

Childhood tuberculosis is one of the global causes of morbidity and mortality especially in endemic areas like Nigeria. Immunodeficiency from any cause may lead to reactivation of primary tuberculosis in children. Increased international travel and migration have threatened to facilitate the emergence and spread of multi-drug resistance TB strains [4].Some studies also revealed that there is a risk for TB infection among internally displaced persons [5]. Our cases were from internally displaced couple and this might lead to the emergence and spread of multi-drug resistance TB in that community.The vast majority of children in endemic areas become infected after 2 to 3 years of age [3]. The first case of this case report may belong to the few that progressed to disease or both cases may have immune-suppression since they havepoor nutritional status which might havepredisposed them to having progressive disease.

Cavitary disease is not a very common finding in children with pulmonary tuberculosis. Ahidjoetal[6] reported that out of 125 children with pulmonary TB 9 were found to be having cavitary lesions given a prevalence of $7.2 \%$. However, cavitary disease in children may result from poor containment at the site oforganism deposition in a very young and/or immune-compromised children, aspiration of live bacilli when a diseased lymphnode erupts into an airway, among those less than 5 years of age, and the third being the adulttype disease found mainly in children greater than 10 years of age [7]. Both cases presented here may have developed cavitary disease due to one of these reasons. Both cases presented here had, in addition to pulmonary cavitary lesions,extrapulmonarymanifestations (lymphatic disease) as about $25-35 \%$ of children with TB haveextrapulmonary presentation [8].The very young nature of the second case and the fact that our cases may be immune-compromised from malnutritioncould explain why the two cases presented withdisseminated disease as documented in the literature [9].

The paucibacillary nature of childhood TB and poor bacteriologic yields coupled withthe fact that Sputum smear microscopy is positive in less than 10 to $15 \%$ of children with probable TB makes the diagnosis of childhood tuberculosis challenging [10].This was in keeping with the finding in these cases as none of them yielded positive results after microbiologic investigations and our diagnosis for these cases was based on the WHO clinical scoring system [11]. Treatment of childhood tuberculosis still remains the use of anti tuberculous drugs, adequate counseling and contact tracing. However, these cases were commenced on anti tuberculousdrugs, counseled but contact tracing could not be done because their parents absconded following the demise of the older sibling and they are internally displaced family secondary to the security challenges in Nigeria.

\section{Conclusion}

Pulmonary cavitary tuberculosis, though rare in childhood, may still occur, especially in the immonocompromised like the malnourished and internally displaced persons. This is because the crowded living conditions of this population can be associated with greater degree of TB transmissionand higher organism burden.Coexisting poor nutritional status of children can also weaken their immune system and make them more vulnerable to developing active TB. It is however difficult to diagnose TB in children due to limitations in the investigations especially in the developing county like ours and the diagnosis is usually clinical. Since these cases occurred in siblings of internally displaced couple, it is imperative to consider the occurrence of progressive TB (adult type of TB) in children in any given setting like this.

\section{References}

[1] Vijayasekaran D, Selvakumar P, Balachandran A, Elizabeth J, Subramanyam L, Somu N. Pulmonary cavitatory tuberculosis in children. Indian Paediatr 1994; 31: 1075 - 1078

[2] Nelson LJ, Wells CD. Global epidemiology of childhood tuberculosis.Int J Tuberc Lung Dis 2004; 8: 636-647

[3] Osinusi K. Tuberculosis in childhood. In: Azubuike JC, Nkanginieme KEO (eds). Paediatrics and Childhealth in a Tropical Region.Second edn. African Educational Service: Owerri, 2007: 634-643.

[4] Newton SM, Brent AJ, Anderson S, Whitteker EKampmann B. Paediatric Tuberculosis. Lancet Infect Dis 2008; 8: 498-510 Weinstock DM. Risk for tuberculosis infection among internally displaced persons in the Republic of Georgia. Int J Tuberc Lung Dis. 2001; 5: 164-169

[5] Ahidjo A, Mustapha MG, Ashir GM, Alhaji MA, Adedokun T. Chest Radiographic Predictors of HIV/ AIDS in Childhood Pulmonary Tuberculosis - An African Study. J Asian SciSci Res 2012; 2: 310-316

[6] Marais BJ, Donald PR, Gie RP, Schaaf HS, Beyers N. Diversity of disease manifestations in childhood pulmonary tuberculosis. Ann Trop Paediatr 2005; 25: 79-86.

[7] Stark JR. Tuberculosis in children. SeminRespirCrit Care Med 2004; 25 (3). www.medscape.com

[8] Bosch VD,Terken M, Ypma L, etal. Tuberculous meningitis and military tuberculosis in young children. Trop Med Int Health 2004; 9: 309-313.

[9] Zar HJ, Hanslo D, Apolles P, Swingler G, Hussey G. Induced sputum versus gastric lavage for microbiological confirmation of pulmonary tuberculosis in infants and young children: a prospective study. Lancet 2005; 365: 130-134.

[10] National TB and Leprosy Control Programme and Federal Ministry of Health. Workers Manual, Revised $5^{\text {th }}$ edition $2010 ; 23-4$. 